\title{
Efecto que Causan los Impuestos Sobre la Demanda de Automóviles en el Ecuador
}

\author{
Effect of Taxes on Automobile Demand in Ecuador \\ *David Fernando Carmona Valarezo ${ }^{1}$, **Nervo Jonpiere Apolo Vivanco ${ }^{1}$

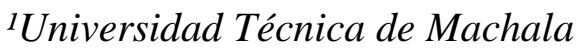 \\ *dcarmona_est@utmachala.edu.ec, **napolo@utmachala.edu.ec
}

Fecha de recepción: 12/06/2020

Fecha de aceptación: 23/06/2020

Publicado: $30 / 06 / 2020$

\section{Resumen}

En el presente trabajo se analiza la importancia de los impuestos y el efecto que estos causan en la demanda de bienes de lujo, delimitando y enfocando el caso en el sector automovilístico, que ha tenido un deterioro pronunciado en las ventas en los últimos años. La conclusión común es que el incrementar impuestos como medida económica disminuye el nivel de ventas especialmente cuando se tratan de bienes de consumo especial. En este sentido el objetivo propuesto en el presente trabajo es analizar los cinco impuestos que deben cancelarse desde que los vehículos ingresan al país para su respectiva nacionalización y comercialización. Se ha utilizado metodología de análisis y síntesis de documentos aplicada con cifras del sector automotriz del periodo 2011-2016, proporcionadas por la Asociación de Empresas Automotrices del Ecuador (AEADE) y la Cámara de la Industria Automotriz Ecuatoriana (CINAE). El estudio es importante porque ayuda a determinar la incidencia que tienen las restricciones en el sector y las causas que han provocado que el gobierno de turno tome estas medidas.

Palabras Clave: impuestos, demanda, restricciones, automotriz.

\section{Abstract}


This paper analyzes the importance of taxes and the effect that they cause in the demand for luxury goods, defining and focusing the case in the automotive industry, which has had a deteriorating pronounced in sales in recent years. The common conclusion is that increasing taxes as an economic measure decreases the level of sales especially when treated special consumer goods. In this sense the objective proposed in this paper is to analyze five taxes that should be canceled from the vehicles entering the country for their respective nationalization and marketing. It has been used methodology of analysis and synthesis of documents, applied with figures of the automotive sector for the period 2011-2016, provided by automotive companies of Ecuador (AEADE) Association and the Chamber of Ecuadorian automotive industry (CINAE). The study is important because it helps determine the incidence that have restrictions in the sector and the causes that have led the Government to take these steps.

Keywords: taxes, demand, restrictions, automotive.

\section{Introducción}

En el desarrollo del artículo se busca enfocar la importancia que tienen los impuestos en la adquisición de bienes de lujo, específicamente en los vehículos utilitarios deportivos (SUV) y el efecto que estos causan en la demanda de los mismos. Se elige esta categoría de vehículo porque son los de mayor valor en cuanto a costos, con excepción de los vehículos de trabajo pesados.

Los impuestos han tenido gran participación en la economía ecuatoriana, cabe destacar que "en una economía dolarizada como la nuestra, la política fiscal es una de las herramientas más poderosas del Gobierno, ya que con ésta puede evitar las grandes fluctuaciones en la actividad económica" (Pico 2015, 39). El estado ha generado políticas fiscales restrictivas para disminuir el shock exógeno de los países vecinos cuando devalúan sus monedas, como las 
salvaguardias y aranceles, aunque el objetivo es proteger la producción nacional se está afectando en forma radical al sector automotriz. Según afirma (Cepeda y Paz 2013) "la materia tributaria nunca ha sido ajena a la política,(...), pues manifiesta el juego de intereses que actúan en la sociedad ecuatoriana a fin de que los impuestos tengan un carácter general, afecten más a unos sectores o a otros". En la toma de políticas fiscales locales se ha afectado tanto a vendedores como a consumidores por las nuevas imposiciones al sector automotriz como normas técnicas de seguridad y la asignación de cupos a las principales importadoras de vehículos, las cuales no pueden tener una libre oferta estando sujetos a tantas restricciones del comercio.

Se sustenta el análisis enfocado desde el punto que el Ecuador es un país subdesarrollado, con un ingreso per cápita promedio en 2011 de $\$ 5.223,38$ y con tendencia creciente en 2015 llegó a \$6.248,68. Si nos permitimos comparar el ingreso per cápita de EE.UU. que es un país desarrollado y su ingreso promedio por habitante es de $\$ 49.781,8$ en el 2011 y \$55.836,78 en el 2015, alrededor de nueve veces más que Ecuador, según cifras del Banco Mundial, donde se considera de lujo un auto de gama alta como la marca Dodge, Porsche, Lamborghini, Ferrari, Audi, Mercedes Benz, Bmw y debido a los ingresos que se generan por habitante pueden acceder a esta clase de vehículos con exorbitantes precios. En Ecuador también existen consumidores de estas marcas, pero son pocas las personas que acceden a un bien suntuario de ese tipo, por lo que no contamos con esa información estadística para concretar un análisis de esta magnitud. Por esta razón, debido a la diferencia que existe en el ingreso, tomando en cuenta que todas las personas no ganan lo mismo y como objeto de estudio, consideramos de lujo a los vehículos utilitarios deportivos SUV's con precios que varían desde 33.000 dólares en adelante, que quizá en otros países son considerados bienes 
normales, pero esta clasificación de bienes de lujo depende de cada país y de la situación económica en que se encuentre.

Como objeto de estudio tenemos los cinco impuestos que pagan los vehículos al entrar al país para su debida nacionalización y comercialización, como es el arancel a las mercancías conocido como 1.- "ad valórem"; está también el impuesto denominado 2.- Fondo de Desarrollo para la Infancia (FODINFA), 3.- el impuesto a salida de divisas (ISD), 4.- el impuesto a los consumos especiales (ICE), y 5.- el impuesto al valor agregado (IVA). A continuación, se presenta una breve evolución de la industria automotriz, más adelante se presenta una tabla de las ventas totales de vehículos y otra tabla segmentada para las ventas de SUV's y el análisis de la situación que ha llevado al gobierno a implementar tales medidas restrictivas. Para concluir se presenta una curva de oferta y demanda ilustrativa para comprender mejor la relación a los precios debido a los impuestos que han tenido los vehículos de lujo.

Para el desarrollo de esta investigación se plantea como objetivo principal el análisis de los impuestos establecidos para la importación, nacionalización y comercialización de vehículos y su impacto en la demanda de estos bienes considerados de lujo.

Para una mejor comprensión se plantean algunos objetivos específicos, tales como: identificar los tributos que se deben pagar y su aplicación al sector automovilístico, establecer el impacto que generan los tributos en la demanda, presentar una curva de oferta y demanda ilustrativa para el análisis. La idea que sustenta el presente trabajo es que, a mayor impuesto al sector automotriz, disminuye la demanda de estos bienes.

Los impuestos o tributos; son generalmente obligatorios y son aplicados según la capacidad financiera de cada persona. "Todos los gobiernos (...) utilizan los impuestos para recaudar 
fondos para financiar proyectos de obras públicas como carreteras, escuelas y defensa nacional" (Mankiw 2009, 121).

Los impuestos se clasifican en dos grupos: directos e indirectos. Existe impuesto directo cuando un trabajador paga el impuesto a la renta o al patrimonio que posee. Los impuestos indirectos son los que se pagan por el consumo de bienes o servicios.

Se dice que los impuestos llegan a ser "la parte central de la política fiscal. Representa una herramienta poderosa que afecta a la demanda agregada influenciando indirectamente la actividad económica y determinando directamente la provisión de bienes públicos” (Barros 2013). Se influencia tanto para contraer la demanda aumentando impuestos o para aumentarla disminuyendo impuestos, según la necesidad de proyección del estado para el corto o largo plazo.

Con el transcurso de los años se ha evidenciado la reacción que tienen los consumidores con relación al incremento de los precios a consecuencia de los impuestos, producto de esto la demanda se contrae por su sensibilidad al aumento de los mismos. Por ejemplo, los individuos deben cancelar el costo base para obtener un vehículo más los impuestos establecidos, aunque sean perjudiciales para su renta y así "tenemos a un Estado ávido de obtener ingresos y a un contribuyente reacio a disponer de sus rentas, motivo por el cual el sistema tributario debe responder a determinados criterios que permitan un equilibrio" (Torrico 2015). Cabe destacar que existen consumidores que prefieren el "lujo" a costa de cualquier precio, tal como lo define (Campuzano 2004) como el "placer de los sentidos sin reparar los costes". Para este tipo de consumidores la demanda es inelástica porque no tienen sensibilidad con la relación al precio. Los vehículos que entren al país deberán cancelar los siguientes impuestos: 
El impuesto para el Fondo de Desarrollo para la Infancia (FODINFA) fue creado para ayudar a los niños ecuatorianos desamparados, para poder cubrir sus necesidades y asigna un impuesto de $(0,5 \%)$, el ad valorem CIF (costo, seguro y flete) a las importaciones se encuentra entre el $35 \%$ y $40 \%$.

El impuesto a la salida de dividas (ISD) ha sido generado para evitar que el país quede sin liquidez, ya que el país no posee moneda propia, y se aplica a la transferencia, envió o traslado de divisas que se efectúen en el exterior, en efectivo o a través de cheques, retiros o pagos de cualquier naturaleza, en este caso a la importación de vehículos y autopartes.

El Impuesto a los Consumos Especiales (ICE), se impone a los bienes y servicios que se realicen dentro del país o a los importados que se detallan en el artículo 82 del grupo 2 de tarifa “ad valorem" de vehículos motorizados de la LORTI $^{1}$ de los cuales contempla valores proporcionales que van del $5 \%$ al $30 \%$ de acuerdo al valor de venta al público de cada automotor.

El Impuesto al Valor Agregado (IVA) se recarga a las transferencias de dominio, a la importación de bienes y a todas sus etapas de comercio como lo mencionan (Amador y Arroba 2017). Con referencia al tema: "este impuesto en el sector importador de vehículos se grava en dos etapas al bien importado: primero la empresa debe cancelarlo para nacionalizar el vehículo y luego el cliente (comprador) lo paga al momento de adquirir el bien”. Esto explica que el IVA sobre los vehículos se grava sobre el mismo impuesto dos veces. Cuando se habla de este tributo "se puede decir que los impuestos que recaen sobre el valor agregado imponen una carga mucho menor para el contribuyente, en la medida en que toman en cuenta una base

\footnotetext{
${ }^{1}$ Ley Orgánica de Régimen Tributario Interno (LORTI), Ecuador: 2016, art. 82, Grupo II Tarifa Ad Valorem
} 
gravable significativamente más pequeña" (Rueda 2014). Posee dos tarifas de $0 \%$ y $12 \%$ y es considerado un impuesto indirecto porque se impone en el consumo o utilización de servicios.

Los aranceles se imponen ante los bienes que se importan y exportan, son establecidos por la autoridad competente y consisten en porcentajes que se aplican al valor de las mercancías, normalmente se gravan a las importaciones para proteger la industria local.

Las salvaguardias arancelarias son una restricción del comercio internacional cuando el país se está viendo afectado por un incremento en las importaciones y como no tiene capacidad de competir con el mercado internacional opta por esta medida para proteger la economía nacional.

\section{Evolución de la Industria Automotriz en el Ecuador}

En la década de los 50, Ecuador inició la elaboración de carrocerías, asientos para buses, piezas metálicas, también se empezó a fabricar neumáticos y baterías. En esta nación se han ensamblado vehículos por más de cuatro décadas; en el año 1973 comenzó la elaboración de vehículos, con un total de 144 unidades con el modelo conocido como Andino, ensamblado por AYMESA hasta el año 1980. En la década de los setenta, se produjeron más de cinco mil vehículos. En el año 1988 con el Plan del Vehículo Popular la oferta se alzó con un 54.21\%, pasando de 7,864 vehículos en 1987 a 12,127 vehículos en 1988. Cuatro años después que se abrieron las importaciones de vehículos con las marcas Chevrolet, Kia y Mazda. En la actualidad, la presencia de ensambladoras multinacionales en Ecuador ha participado con nueva tecnología la cual, ha ayudado a mejorar el ensamblaje y creación de autopartes, lo cual ha contribuido con el desarrollo de la industria automotriz.

La industria automotriz es de vital importancia para la economía ecuatoriana en cuanto a la recaudación de impuestos y generación de empleo, ya que aporta positivamente a las 
exportaciones, e importaciones de vehículos y autopartes. Es un dinamizador de la economía, generando desarrollo y promoviendo el tan mencionado "modelo de industrialización". Este modelo se basa en la sustitución de importaciones, aunque estas pueden llegar a ser beneficiosas "si se considera el consumo intermedio, las importaciones pueden contribuir a que los productores locales ganen productividad, sin embargo, puede reducir los encadenamientos locales de otras industrias domésticas, a menos que exista una política industrial orientada a la creación de capacidad de producción con alta productividad” (Santeliz y Contreras 2014).

Cuando refiere al termino encadenamientos locales son medios para integrarse a la economía global y mejorar sus procesos productivos, es decir, empresas dedicadas a la misma actividad que se unen para mejorar, actualizar conocimientos y poder competir con las empresas internacionales, pero si estos se reducen generarían más productividad y competencia entre las industrias locales, la política debe generar un ambiente propicio para que se lleve a cabo. Dicho esto, no solo se debe restringir las importaciones sino integrar a las empresas locales para que se beneficien de estas medidas más no que les afecte.

\section{Demanda de bienes de lujo (automóviles SUV's)}

En el artículo de (Salvador y Montes 2016) nos dicen que el lujo proviene del latín luxus que significa "exceso o extravagancia" e "indulgencia viciosa". Demandar un bien de lujo como un automóvil utilitario deportivo es una necesidad secundaria, después de satisfacer las necesidades básicas, si el individuo cuenta con renta disponible, aumenta su poder adquisitivo de algún transporte ostentoso distintivo. Se dice que "el afán por poseer artículos de lujo proviene de épocas remotas y ha sido tradicionalmente relacionado con la exclusividad y la diferenciación del individuo dentro de los distintos estratos sociales y periodos históricos" 
(Liberal y Sierra 2013). Los consumidores de automóviles deportivos de lujo buscan tener una apariencia distintiva ante la sociedad.

Los atributos que nos ayudan a diferenciar un bien de lujo como un automóvil "están ligados a aspectos como materiales utilizados, las tradiciones que involucran, las formas y símbolos que los identifican, los tipos de compradores, la maestría de los artesanos que los elaboran, etc.”(Uribe 2006). Las características son especiales, que aportan elegancia, tecnología, mayor potencia y durabilidad por lo cual también incrementan sus precios.

\section{Materiales y Métodos}

La revisión de la literatura tanto nacional como internacional ofrece una amplia gama de información acerca de los impuestos aplicados por la importación de vehículos desde el punto de vista teórico y práctico. Páginas Web y documentos oficiales de entidades estatales proporcionaron información sobre la evolución de la industria automotriz en Ecuador. Se grafica la curva de la demanda y de la oferta para analizar la relación de las variables y se calcula el coeficiente de correlación de Pearson para determinar el nivel de correlación entre las variables.

El tipo de estudio descriptivo, realizado en esta investigación, utiliza el método de análisis de documento referentes al peso de los impuestos en la demanda, los mismos que facilitaron una sistematización de los elementos teóricos relacionados con esta temática.

\section{Resultados}

Analizando la evolución en ventas totales de los todos los vehículos vendidos son de vital importancia porque van a servir como herramienta para tener un enfoque global y poder medir el crecimiento o disminución de la demanda. Sin embargo, como información adicional se puede destacar que están integradas por automóviles, suv’s, van, camiones, buses, camionetas y 
algunos de estos no son considerados de lujo porque son vehículos que son utilizados para trabajo, como por ejemplo transporte de pasajeros o vehículos de carga pesada.

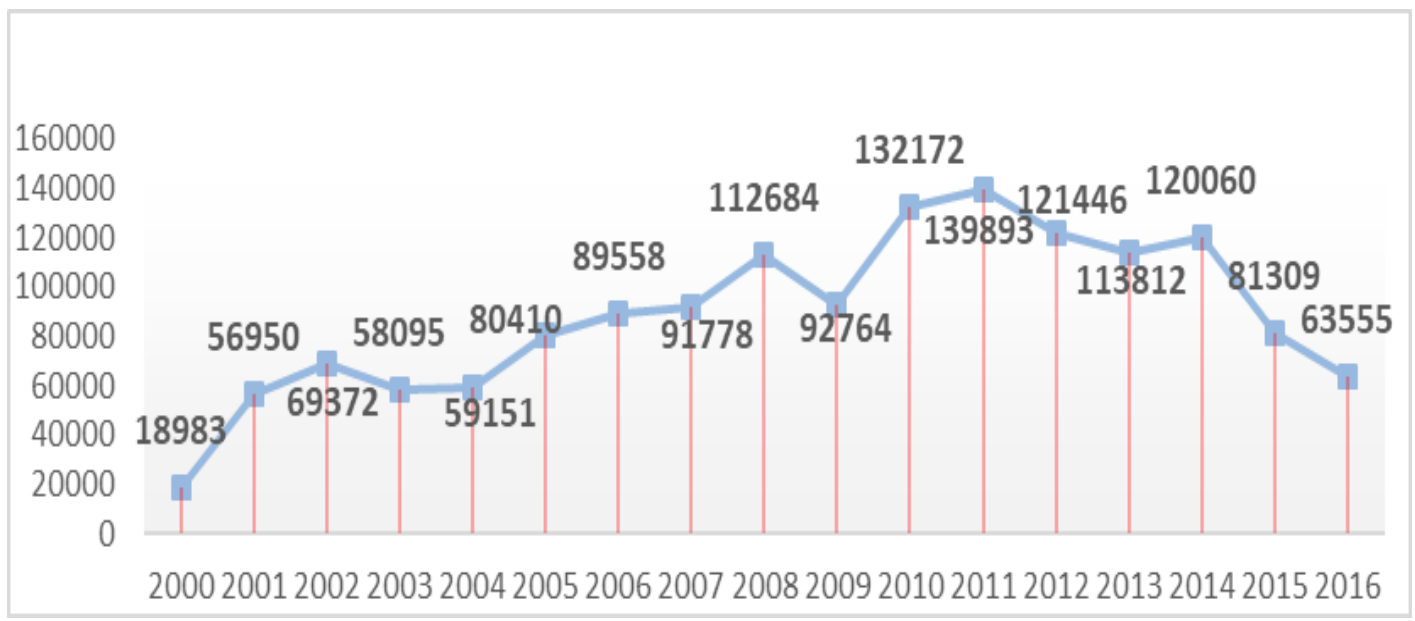

Fig. 1. Ventas por unidades de Vehículos, Fuente: Anuario 2016, (AEADE)

En este gráfico se observa una tendencia creciente en las ventas partiendo del año 2000, antes de esto el país atravesó por una crisis bancaria, inflación y recesión desatadas por malas políticas económicas, para posteriormente adoptar el dólar como moneda oficial de circulación y estabilizar la economía y hacer que el sector automotor crezca de manera acelerada en un $243,32 \%$ de 2000 a 2005 . Sólo en el primer año se disparan las ventas en un $200 \%$ tal como se observa en el gráfico. La disponibilidad de créditos de consumo hizo más asequible la compra de vehículos nuevos para la clase media, dinamizando así la industria y el mercado ${ }^{2}$. De 2006 a 2011 el crecimiento en ventas es de 67,28\%. Pero la serie marca un declive notable de 2008 a 2009 debido a la crisis financiera que inició en EE.UU. y contagió a todas las economías a nivel global, a pesar que Ecuador no pertenecía a los mercados financieros internacionales debido a su situación moratoria con la deuda externa, se vio afectado por la caída del precio del

\footnotetext{
${ }^{2}$ Anuario 2017, Cámara de la Industria Automotriz Ecuatoriana (CINAE)
} 
barril de petróleo a finales de 2008 hasta mediados de $2009^{3}$, el sector automotriz se recupera y vuelve a resurgir en sus ventas hasta 2011 gracias al incremento de los precios del petróleo.

Debido a esos shocks externos el gobierno ha tenido que implementar políticas de austeridad para una economía en crisis y una de ellas ha sido el incremento de impuestos. (Velázquez y González 2016) Pero para implementar estas medidas "en muchos países la experiencia de reformas fiscales en las últimas décadas revela que un dilema típico en los esfuerzos por reformar sistemas tributarios se da casi inevitablemente entre los objetivos de recaudar más y ser al mismo tiempo equitativos" (Casares et al. 2015). Esto es justo lo que ha sucedido en nuestra economía que ha seguido el paradigma y se ha excedido en carga impositiva. Pero, las razones que llevo al gobierno a tomar estas medidas restrictivas, fue por que la economía venia afrontando un déficit comercial (importaciones son mayores a las exportaciones) desde que inició la dolarización, y para frenar el déficit una de las medidas adoptadas por el COMEX (Ministerio de Comercio Exterior) en el mes de agosto del 2011 estableció un régimen de registro de importadores con el objetivo de restringir en 20\% la importación de vehículos y posteriormente reemplazo este registro de importadores por un régimen de licencias previas de importación con el objetivo de frenar las importaciones de las empresas que excedieron el monto de $80 \%$. Este mismo año, el 24 de noviembre, se puso en marcha la ley de fomento ambiental y optimización de los ingresos del estado, la cual trajo algunas modificaciones tributarias. Uno de esos cambios fue el aumento del ISD del 2\% al 5\%.

El problema que se hizo global, fue la crisis del techo de la deuda de EEUU y la crisis de la zona euro, que puso en jaque las exportaciones de Ecuador, por ende, las ventas de vehículos se empezaron a desplomar.

\footnotetext{
${ }^{3}$ Elcomercio.com, Vicente Albornoz Guarderaz, "La crisis del 2008", acceso el 10 de julio de 2017, http://www.elcomercio.com/opinion/crisis-del-2008.html
} 
El 2012 fue un año bueno para la economía ecuatoriana "se benefició del crecimiento económico y de un aumento en gastos sociales alcanzando varios logros internos, tales como la disminución de la pobreza y la desigualdad" (Polga 2013), pero el sector automotor se ve afectado por la resolución 65 y 66 del COMEX, la primera aplicada el 11 de junio, la cual implica una restricción cuantitativa anual a la importación de CKD (Kit para Ensamblaje) de vehículos clasificados en subpartidas y la segunda adoptada el 11 de julio, la misma que establece una restricción cuantitativa anual a la importación de vehículos.

Para el 2013, el proyecto de Reforma RTE INEN 034 (Elementos mínimos de seguridad para vehículos automotores), en el que se plantea la incorporación de nuevos elementos de seguridad para los vehículos como luces de encendido automático, avisador acústico de no uso de cinturón de seguridad, doble airbags frontales, limitador de velocidad, etc. Lo cual generaría costos de implementación y lo que encarecería aún más los vehículos.

En 2014, la venta de vehículos crece en 5,43\%. La demanda para este año fue atípica, la cual empezó a incrementarse en el mes de septiembre obedeciendo a un adelantamiento de la decisión de compra por parte de los usuarios, ante la incertidumbre generada en torno a las posibles medidas gubernamentales que inciden directamente en el precio de los vehículos nuevos ${ }^{4}$.

Para 2015, se evidencia un decrecimiento de $-32,28 \%$ como consecuencia de las medidas antes impuestas. Para 2016, sigue a la baja en un $-21,84 \%$, lo que influenció este año fue el terremoto del 16 de abril que afectó a la costa ecuatoriana y a todo el país. Producto de esto se aprobó la Ley de Solidaridad y Corresponsabilidad Ciudadana que empezó a regir desde el 1 de junio de este año, una de las medidas contenidas en esta ley es el incremento del IVA de

\footnotetext{
${ }^{4}$ Anuario 2014, Asociación de Empresas Automotrices del Ecuador (AEADE)
} 
12 a $14 \%$ lo cual repercutió directamente en las ventas del sector automotriz y toda la economía, obteniendo este año la peor venta de vehículos en los últimos doce años.

En el gráfico a continuación va delimitando el tema y enfocando el análisis de los seis últimos años a los vehículos utilitarios deportivos más conocidos como su abreviatura en inglés SUV, que dentro del análisis lo consideramos un vehículo de lujo porque no son de fácil acceso para toda la población por el nivel de precios que estos vehículos demandan.

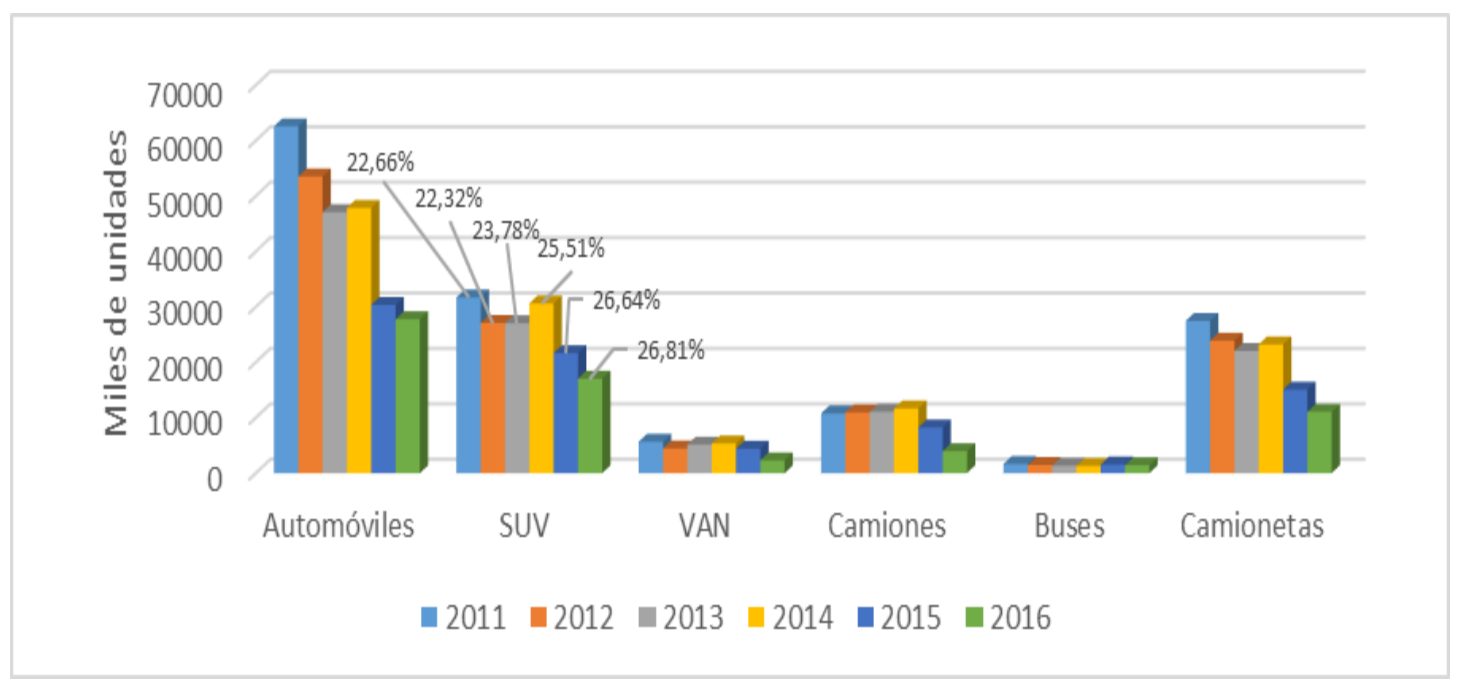

Fig. 2. Ventas por Segmento

Se puede observar que la demanda de automóviles es la más destacada, aunque tiene tendencia a la baja, pero ha tenido mayor participación en ventas por los precios que son más accesibles. Los SUV's que han tenido una participación en las ventas totales desde el 2011 con un 22,67\% hasta el 2016 con un 26,82\% pero este porcentaje no indica que las ventas hayan crecido porque en otras categorías de vehículos han disminuido las ventas y el valor total no ha sido el mismo durante todos los años. A continuación, el siguiente gráfico muestra las ventas por unidades de los vehículos utilitarios deportivos. 


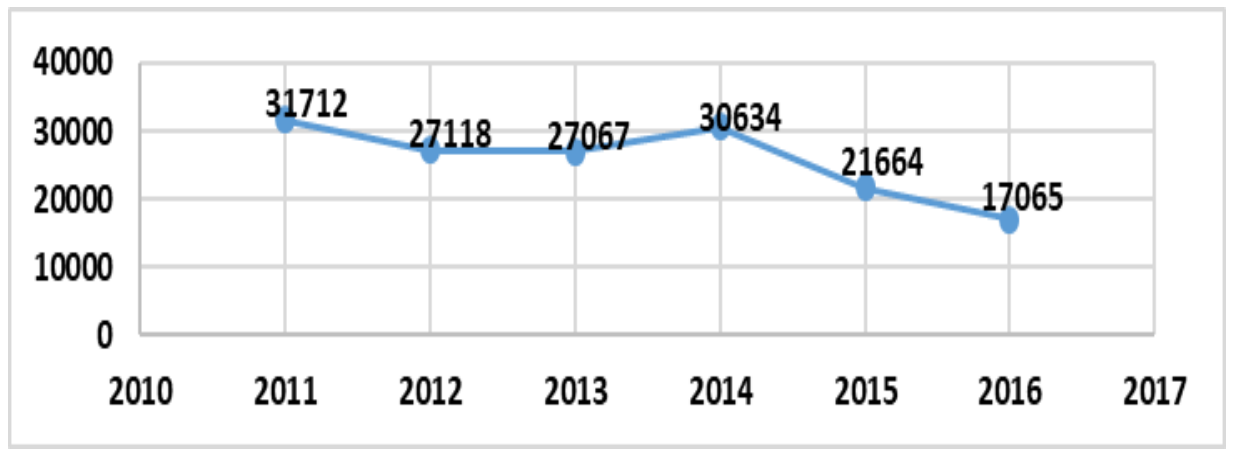

Fig. 3. Ventas de SUV's 2011-2016

En el grafico observamos que la demanda en los vehículos de lujo SUV's de 2011 a 2012 disminuyó en un $-14,49 \%$, de 2012 a 2013, existe una variación mínima de -0,19\%, de 2013 a 2014, repunta con un valor positivo de 13,18\%, del 2014 al 2015 vuelve a sufrir un decremento la demanda en un -29,28\% y para el periodo 2015 a 2016 sigue la tendencia a la baja en un 21,23\%, ocasionando una marcada disminución de la demanda de vehículos SUV's.

Tabla 1. Precios Promedio de Ventas de Vehículos según Segmento en dólares 2011-2016

\begin{tabular}{lcccccc}
\hline CATEGORÍA & $\mathbf{2 0 1 1}$ & $\mathbf{2 0 1 2}$ & $\mathbf{2 0 1 3}$ & $\mathbf{2 0 1 4}$ & $\mathbf{2 0 1 5}$ & $\mathbf{2 0 1 6}$ \\
\hline AUTOMÓVILES & 18933 & 19815 & 21370 & 23550 & 23540 & 23421 \\
CAMIONETAS & 27485 & 29775 & 31549 & 32795 & 35207 & 37805 \\
SUV & $\mathbf{3 3 7 2 5}$ & $\mathbf{3 6 8 0 4}$ & $\mathbf{4 0 7 0 1}$ & $\mathbf{4 3 6 4 7}$ & $\mathbf{4 3 7 1 9}$ & $\mathbf{4 5 5 4 3}$ \\
VAN & 24471 & 26175 & 28697 & 29089 & 28849 & 33563 \\
CAMIONES & 51160 & 53252 & 59557 & 60397 & 55331 & 56167 \\
BUSES & 55208 & 67063 & 69307 & 78988 & 72976 & 82061
\end{tabular}

Fuente: Anuario 2016, (AEADE) Elaboración: Los autores

Se toma esta tabla como referencia para hacer una comparación de precios y se observa que los precios marcan una tendencia creciente a partir del 2011 a 2012 un incremento de 9,13\% en el nivel de precios; de 2012 a 2013 se incrementa en 10,59\%; para el 2013 a 2014 el 
alza fue de 7,24\%; de 2014 a 2015 sigue manteniendo el alza con un porcentaje mínimo de 0,16\% y para periodo comprendido de 2015 a 2016 el incremento fue de $4,17 \%$.

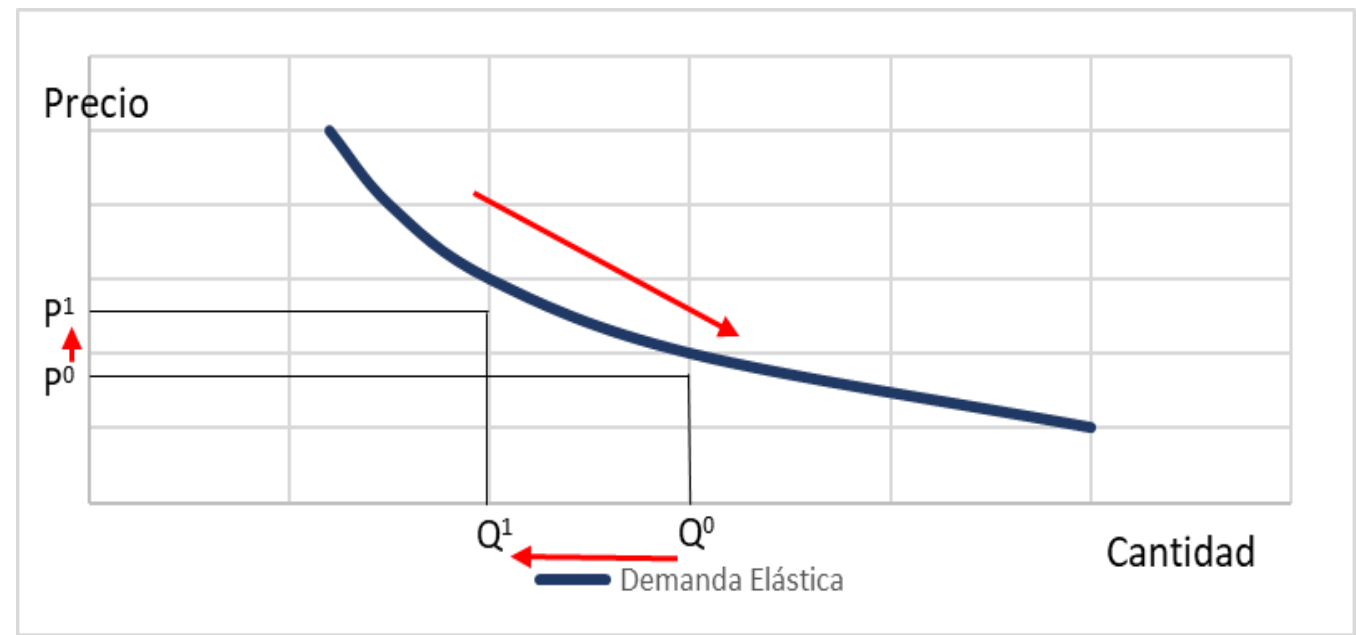

Fig. 4. Demanda Elástica

Para finalizar graficamos una curva de demanda donde observamos cuando el precio $\mathrm{P}^{0}$ aumenta a $\mathrm{P}^{1}$, la cantidad $\mathrm{Q}^{0}$ disminuye $\mathrm{Q}^{1}$. Se cumple el concepto de elasticidad del impacto que tiene el precio sobre la cantidad demandada, es decir, a mayor precio menor cantidad demandada.

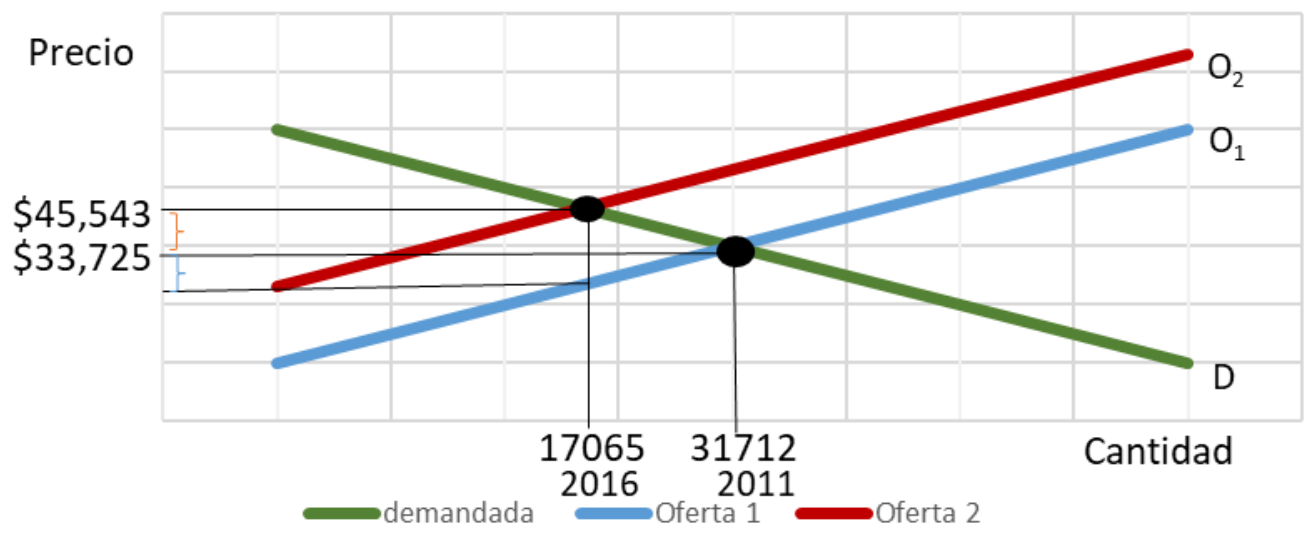

Fig. 5. Curvas de Oferta y Demanda de SUV's 
Para complementar el análisis se observa en el grafico tres curvas de oferta y demanda. La Curva $\mathrm{O}^{1}$ intercepta y forma un punto de equilibrio con la Curva de demanda "D" en el año 2011 con un precio promedio inicial de vehículos utilitarios deportivos de $\$ 33.725$ y con 31.712 unidades. Luego, para el 2016 el precio promedio se incrementó a $\$ 45.543$, lo cual crea el desplazamiento dentro de la curva de demanda y crea una nueva curva de oferta y punto de equilibrio, reduciendo la cantidad demandada a 17.065 unidades.

Por último, calculamos el coeficiente de correlación de Pearson, obteniendo un coeficiente de -0,644 que denota una correlación inversa moderada entre las variables cuantitativas, se observa el cumplimiento del fenómeno en Ecuador de que cuando los precios de los vehículos SUV's aumentan la demanda disminuye.

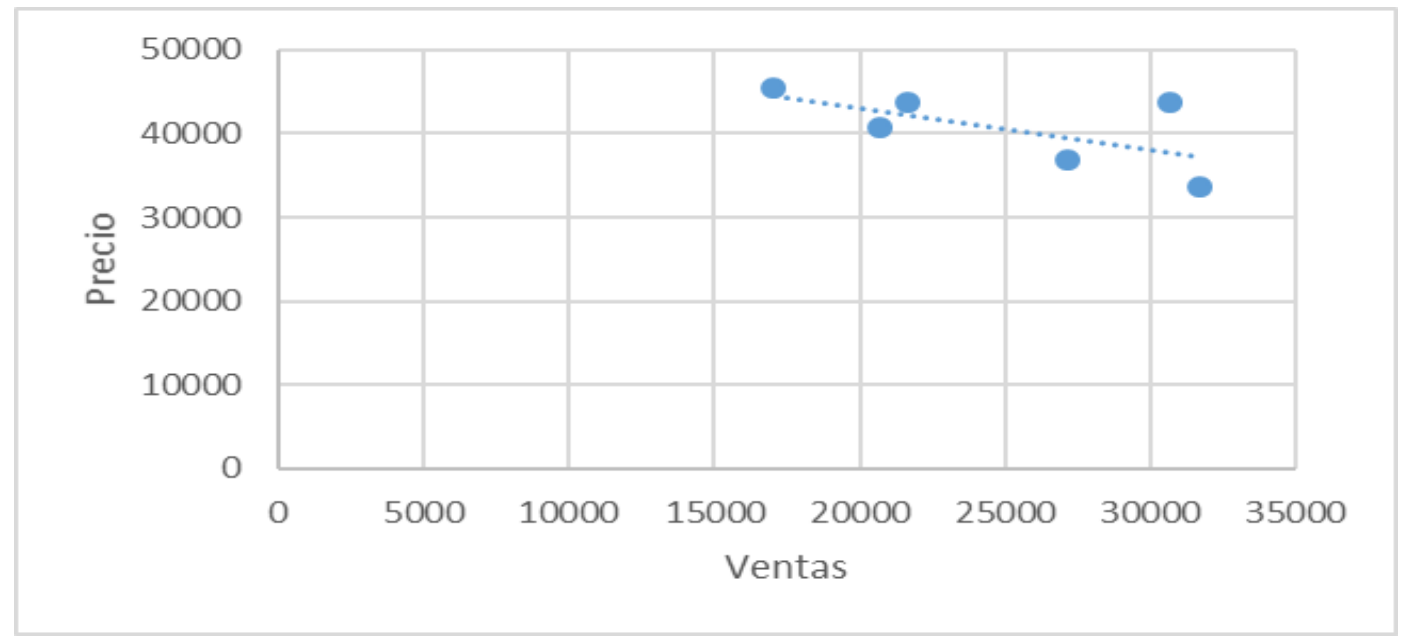

Fig. 6. Correlación de Pearson

\section{Conclusiones}

El gobierno adoptó medidas impositivas para el comercio internacional en su afán de gravar más impuestos a quienes poseen mayores ingresos, quizás esta medida cumplió con el objetivo de reducir importaciones, pero produjo una marcada disminución en el nivel de ventas de vehículos, lo cual afectó al sector automotor del país. Influir en la economía mediante el 
incremento de la carga fiscal no es aconsejable ya que con el tiempo la economía suele regularse por el dinamismo del mercado y produce complicaciones al sector afectado por los impuestos.

La cantidad excesiva de impuestos puso en jaque la renta de los demandantes, se observa un decrecimiento de la cantidad demanda que en el 2011 donde se vendían 31.712 unidades y para el 2016 se vendieron 17.065, disminuyendo alrededor del 50\% de las ventas de vehículos SUV's en el país. Esto denota una elasticidad relativa ya que el incremento de los precios en un 35\% en el 2016 en comparación al 2011 produjo un efecto negativo en la venta de vehículos que disminuyó en un 46,19\% en el mismo periodo.

La asignación de cupos de importación también ha sido otra determinante primordial que ocasionó la contracción de la demanda de vehículos de lujo SUV, afectando al sector automotriz que genera empleo y aporta tributos al estado. Cabe destacar que no solo los impuestos han tenido influencia en el deterioro en la demanda de vehículos de lujo SUV, sino también se ha debido a shocks exógenos que han golpeado la economía ecuatoriana y por ende el poder adquisitivo de las personas.

Los vehículos tipo SUV's son bienes que tiene muchos sustitutos y esto se ve en el mercado con la gran variedad de tipos de vehículos que se ofrecen en el sector automotriz, es por eso que presenta una demanda relativamente elástica, además también se observa que si el precio aumenta un poco o es más costoso que los otros vehículos su cantidad demandada disminuye, ya que los consumidores abandonarán el uso de este tipo de vehículos, este análisis adquiere mayor robustez al obtener un coeficiente de correlación de -0,644.

\section{Bibliografía}

Amador Zambrano, Carlos Elías, and Inés María Arroba Salto. 2017. “Los Impuestos 
Tributarios de Las Importaciones de Vehículos Y Su Incidencia En La Rentabilidad Del Sector Automotriz." Revista Observatorio de La Economía Latinoamericana. http://www.eumed.net/cursecon/ecolat/ec/2017/impuestos.html.

Barros, Bruno. 2013. “Por Qué Las Personas Pagan Sus Impuestos?” Subjetividad Y Procesos Cognitivos 17 (2): 37-47. http://www.redalyc.org/articulo.oa?id=339630262002.

Campuzano, Susana. 2004. “La ‘esencia’ Del MARKETING Del Lujo.”

Casares, Enrique, Maria Garcia, Lucia Ruiz, and Horacio Sobarzo. 2015. "DISTRIBUCIÓN DEL INGRESO, IMPUESTOS Y TRANSFERENCIAS EN MÉXICO. Un Análisis de Equilibrio General Aplicado.” El Trimestre Económico LXXXII (3): 523-58.

Cepeda, Miño, and Juan Paz. 2013. Historia de Los Impuestos En Ecuador.

Liberal Ormaechea, Sheila, and Javier Sierra Sánchez. 2013. "Los Atributos Definitorios de Una Marca de Lujo Para Los Consumidores." Intangible Capital, 9() 903-930. http://www.redalyc.org/articulo.oa?id=193414423004.

Mankiw, N Gregory. 2009. Principios de Economía. Sexta Edic. México: Cengage Learning. Pico, Ana. 2015. "Impuesto a Los Consumos Especiales Y Su Incidencia En El Consumo Del Cigarrillo En El Ecuador Período 2007 - 2013.”

Polga, John. 2013. "Ecuador: Estabilidad Institucional Y La Consolidación de Poder de Rafael Correa." Revista de Ciencia Política 33: 135-60. doi:10.4067/S0718$090 \times 2013000100007$.

Rueda, David. 2014. "Implicaciones de La Creación Del Impuesto Nacional Al Consumo En Los Aspectos Fiscales Y Penales.” Revista de Derecho Privado 51: 1-20.

Salvador, Andrea, and Manuel Montes. 2016. "La Identidad Visual Del Lujo En España." Prisma Social 17: 1-23. 
Santeliz, Andrés, and José Contreras. 2014. “Comportamiento de La Industria Manufacturera En Diferentes Países (Análisis de Su Dinámica Histórica).” Revista Venezolana de Análisis de Coyuntura, Enero-Junio, 39-70.

Torrico, Mauricio. 2015. "El Sistema Tributario En El Modelo de Estado Autonómico Boliviano." Ciencia Y Cultura 35: 219-34.

Uribe, Carlos. 2006. “Atributos Característicos de Las Marcas de Bienes de Lujo.” AD-Minister 8: $27-50$.

Velázquez, Daniel, and Diana González. 2016. “Impuestos Y Deuda Pública: Una Relación Paradójica." Revista Facultad de Ciencias Económicas: Investigación Y Reflexión XXIV: 7-28. 